\title{
Delineating the Type 2 Diabetes Population in the Netherlands Using an All-Payer Claims Database: Specialist Care, Medication Utilization and Expenditures 2016-2018
}

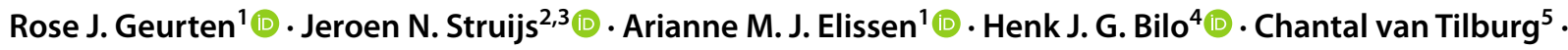 \\ Dirk Ruwaard ${ }^{1}[$
}

Accepted: 4 October 2021 / Published online: 4 December 2021

(c) The Author(s) 2021

\begin{abstract}
Objectives The aim of this study was to describe the healthcare utilization and expenditures related to medical specialist care and medication of the entire type 2 diabetes population in the Netherlands in detail.

Methods For this retrospective, observational study, we used an all-payer claims database. Comprehensive data on specialist care and medication utilization and expenditures of the type 2 diabetes population ( $n=900,522$ in 2018) were obtained and analyzed descriptively. Data were analyzed across medical specialties and for various types of diabetes medication (or glucose-lowering drugs [GLDs]) and other medication.

Results Specialist care utilization was diverse: different medical specialties were visited by a considerable fraction of the type 2 diabetes population. Total expenditures on specialist care were $€ 2498$ million in 2018 (i.e., $10.6 \%$ of the national specialist care expenditures). In total, 97.8\% of patients used other medication (not GLDs) and 81.8\% used GLDs; $25.6 \%$ of medication expenditures were for GLDs. For both specialist care and medication, mean expenditures per treated patient were higher than median expenditures, indicating a skewed distribution of spending.

Conclusion Use of and expenditures on specialist care and medication of the type 2 diabetes population is diverse. These heterogeneous healthcare use patterns are likely caused by the presence of comorbidities. Additionally, we found that a small fraction of the population is responsible for a large share of the expenditures. A shift towards more patient-centered care could lead to health improvements and a reduction in overall costs, subsequently promoting the sustainability of healthcare systems.
\end{abstract}

Rose J. Geurten

r.geurten@maastrichtuniversity.nl

1 Department of Health Services Research, CAPHRI Care and Public Health Research Institute, Faculty of Health, Medicine and Life Sciences, Maastricht University, Maastricht, The Netherlands

2 Department of Quality of Care and Health Economics, Center for Nutrition, Prevention and Health Services, National Institute of Public Health and the Environment (RIVM), Bilthoven, The Netherlands

3 Department of Public Health and Primary Care, Leiden University Medical Centre, Campus The Hague, The Hague, The Netherlands

4 Department of Internal Medicine, University Medical Center Groningen, Groningen, The Netherlands

5 Vektis Health Care Information Center, Zeist, The Netherlands

\section{Key Points for Decision Makers}

Specialist care and medication use patterns of patients with type 2 diabetes are heterogeneous, indicating diverse care needs and the potential value of more tailored, patient-centered care.

A small part of the type 2 diabetes population is responsible for a large share of total expenditures. Further insight is needed into the characteristics of these 'highneed, high-cost' patients.

Exploiting the value of all-payer claims databases for diabetes cost studies can support decision making and promote the sustainability of healthcare systems. 


\section{Introduction}

Worldwide, the burden of chronic diseases is quickly rising $[1,2]$. One of the most prevalent chronic diseases is diabetes mellitus, which affects an estimated $9.3 \%$ of adults in the 20-79 years age group [3, 4]. Within the diabetes population, over $90 \%$ of patients suffer from type 2 diabetes [4, 5]. Many patients with type 2 diabetes do not only use diabetes-related care but also use care across the healthcare system for comorbidities, such as chronic obstructive pulmonary disease (COPD) or heart failure [6-12]. Almost all type 2 diabetes patients utilize medical specialist and pharmaceutical care. Consequently, the largest burden in spending is due to hospitalizations, followed by outpatient specialist care and medication [13-15]. Type 2 diabetes patients are hospitalized at approximately twice the rate of the non-diabetes population, with longer average lengths of stay, and readmission is more common than for people without diabetes $[15,16]$. Additionally, outpatient specialist care is used by the majority of type 2 diabetes patients [17]. Medication use for comorbidities increases total expenditures even further as non-diabetes medication costs are usually higher than costs for diabetes medication (i.e., glucose-lowering drugs [GLDs]) [9]. Therefore, other medication (not GLDs) can substantially increase pharmaceutical expenditures of a patient with type 2 diabetes [9].

Despite the increased use of medical specialist care and medication, studies providing more complete and detailed insight into the utilization and expenditures of inpatient and outpatient medical specialist care (hereafter called specialist care) and medication of the type 2 diabetes population are scarce. Prior research often focuses on subgroups of the type 2 diabetes population; for instance, determined by patients who suffered a specific event, geographically defined groups, insurance defined groups, patients of specific care organizations, or random samples [7-9, 18-24]. Thus, the use of data representing a heterogeneous, nationwide type 2 diabetes population is rare [19]. Additionally, studies on specialist care use often focus on a specific medical specialty or type 2 diabetes complication $[6,8,18,20]$. Thus, insight into total specialist care utilized by type 2 diabetes patients remains limited. Regarding medication use, research often concentrates on a specific type of diabetes medication and, for instance, its effect on type 2 diabetes-related complications [16, 25]. Moreover, many medication studies only address diabetes medication and ignore utilization of other medication $[11,13]$.

Since almost all patients with type 2 diabetes use specialist and pharmaceutical care, a complete insight into this heterogeneous population and their use and spending is needed to support better decision making to realign services and expenditures and promote long-term sustainability of healthcare systems [26]. Accordingly, the aim of this study is twofold. First, we aimed to describe in detail the specialist care utilization and expenditures of the type 2 diabetes population across medical specialties (e.g., internal medicine, cardiology) over the years 2016-2018, and second, we aimed to specify the use of and expenditures on diabetes medication, as well as other medications, for the same population over the same time period. To fulfill these aims, we used an all-payer claims database (APCD) that covered $99.9 \%$ of the Dutch population. This enabled analysis of the services used and expenditures of the total type 2 diabetes population across the entire health system and over time $[27,28]$.

\section{Methods}

\subsection{Data Source}

This retrospective, observational study was based on an APCD managed by the Vektis Health Care Information Center. In 2006, Vektis was established by Dutch health insurers to combine and interpret reimbursement data and enable the main players in the Dutch healthcare market to base decisions and policy on reliable, essential, and timely information. Moreover, Vektis delivers claims data necessary for the risk equalization model to prevent risk selection [29]. For these objectives, the APCD contains information on all procedures covered by Dutch statutory health insurance and a set of data on patients, providers, care products, and prices. The information center now receives data from all Dutch health insurers and covers virtually all Dutch citizens $(99.9 \%)$. For this study, comprehensive claims data regarding the type 2 diabetes population, their specialist care and medication utilization, and reimbursements from 2016 to 2018 were drawn from the Vektis registry. We chose the timeframe 2016-2018 because it is the most recent time frame for which complete claims data from all healthcare sectors is available at Vektis.

\subsection{Study Population}

The type 2 diabetes population was identified using claim codes indicating integrated diabetes care and/or Anatomical Therapeutic Chemical (ATC) codes describing medication use for type 2 diabetes. In the Netherlands in $2018,83 \%$ of type 2 diabetes patients received integrated diabetes care within the primary care setting [30]. Integrated diabetes care is organized by a contracting entity (i.e., care groups) comprised of general practitioners (GPs) and affiliated or subcontracted personnel, and is funded based on a bundled 
payment per patient per year [31]. As $80 \%$ of type 2 diabetes patients were estimated to use diabetes medication, ATC codes were used to identify the type 2 diabetes patients who did not receive integrated diabetes care [32].

Thus, to be as exact as possible, individuals were identified as having type 2 diabetes if they met one or more of the following criteria at any time during the corresponding year: (1) received integrated diabetes care, or (2) were treated for type 2 diabetes with (2a) only oral medication (A10B blood glucose-lowering drugs, excluding insulins); (2b) a combination of insulin (A10A insulins and analogues for injection) and oral medication (A10B blood glucose-lowering drugs, excluding insulins); or (2c) a combination medication (A10AE54 or A10AE56: a mix of insulins and glucagon-like peptide 1 [GLP-1] for injection, long-acting). No exclusion criteria were utilized. For the timeframe of this study, the type 2 diabetes population was determined separately for each year. Accordingly, the study population had the nature of an open and dynamic cohort, in which individuals could be added to or excluded from the cohort each year. As such, we could study the total type 2 diabetes population and its changes over time. In 2018, the type 2 diabetes population prevalence was 900,522 people (6.5\% of the Dutch population aged 18 years and above), which was an increase of $2.3 \%$ compared with $2016(n=880,121)$. The mean age of the population was 68.7 years $( \pm 12.3)$ and $46.7 \%$ of the population were female in 2018 (Table 1).

\subsection{Variables of Interest}

\subsubsection{Specialist Care Utilization and Expenditures}

In the current study, we analyzed specialist care utilization and expenditures of the type 2 diabetes population, both

Table 1 The Dutch type 2 diabetes population 2016-2018

\begin{tabular}{llll}
\hline & 2016 & 2017 & 2018 \\
\hline $\begin{array}{l}\text { Annual prevalence, } \\
n\end{array}$ & 880,121 & 890,682 & 900,522 \\
$\begin{array}{l}\text { New patients, } n \\
\text { Loss to follow-up, } n\end{array}$ & 58,606 & 57,877 & 57,411 \\
$\quad$ Deceased & 38,042 & 38,962 & 40,050 \\
$\quad$ Other reasons ${ }^{\text {a }}$ & 19,055 & 9274 & 8609 \\
$\begin{array}{l}\text { Mean age, years } \\
\quad \text { SD) }\end{array}$ & $67.4( \pm 12.4)$ & $68.5( \pm 12.4)$ & $68.7( \pm 12.3)$ \\
Sex, female, $n(\%)$ & $417,912(47.5)$ & $419,658(47.1)$ & $420,988(46.7)$ \\
\hline
\end{tabular}

$S D$ standard deviation

${ }^{\text {a }}$ Other reasons for loss to follow-up include people who no longer met the inclusion criteria, people admitted to a nursing home, and people who emigrated. Calculated as (number of patients $y-1)+$ (number of new patients $y$ ) - (number of deceased $y-$ ) - (number of patients $y$ ) related and unrelated to diabetes. By care related to diabetes, we considered care to treat diabetes directly: the integrated diabetes care program (including tests and care for common related complications, e.g. diabetic foot care and fundus photography), diabetes medication (i.e. A10 medication), and specialist care for diabetes by the internist. All other care was considered unrelated to diabetes in this paper. In the Netherlands, specialist care (i.e., care provided in hospitals and independent specialized treatment centers) is reimbursed via 'diagnosis-treatment combinations' (DTCs; in Dutch: diagnose-behandelcombinatie [DBC]). A DTC is linked to a specific medical specialty and covers the complete process of care and thereby involves information on specialism or the responsible specialized physician, patient diagnosis, and provided treatment. One DTC may include several healthcare consultations, tests, or treatments. In this study, DTCs were used to assess specialist care utilization as well as expenditures. To examine specialist care utilization, we determined the share of the population that had DTCs under a specific medical specialty, as well as the number of different medical specialties patients with type 2 diabetes consulted annually.

To determine the expenditures per medical specialty, a median Dutch price per DTC was calculated by Vektis. This median DTC price was used to allow a more uniform approach of costs and cost development; as in practice, the prices for specific DTCs differ between hospitals and do not necessarily reflect the true costs of the related care episode [33]. Variations between hospitals arise due to differing contractual agreements between individual hospitals and health insurers [34]. Moreover, for administrative purposes, hospitals occasionally recalculate the prices of specific DTCs to meet the hospital global budget. To mitigate the variation in expenditures and better reflect true costs, we used the median price per DTC to calculate the specialist care expenditures. The median DTC price was determined separately per specific DTC and for each study year. All countrywide reimbursed DTCs of a specific type were arranged to find the median. Finally, to determine the total expenditures per medical specialty, the associated number of reimbursed DTCs were multiplied with the related median DTC prices.

\subsubsection{Medication Utilization and Expenditures}

In consideration of the medication utilization and expenditures of the type 2 diabetes population, we identified multiple subgroups regarding the total use of medication and use of diabetes medication specifically (i.e., GLDs). Regarding total medication use, the subgroups were constructed based on the use of (1) GLDs (A10); (2) other medication, but not GLDs (A10); (3) both GLDs (A10) and other medication; and (4) no form of medication. For diabetes medication or GLDs specifically, five subgroups were distinguished based on the patients' use of (1) oral medication (A10B); (2) 
insulins (A10A); (3) both insulin and oral medication (A10A and A10B); (4) a mix of insulin and GLP-1 for injection, long-acting (insulin/GLP-1: A10AE54 or A10AE56); and (5) no form of GLD. In this study, the medication expenditures were based on the purchase price of the medication, as calculations from Vektis show that the purchase price is equal to the reimbursed medication costs. Total expenditures per medication subgroup, as well as mean and median medication expenditures per treated patient, were assessed.

\subsection{Statistical Analysis}

Data were analyzed descriptively. The continuous variables of age and mean expenditures per treated patient were presented as means and standard deviations (SDs). The specialist care and medication expenditures were also described by the median expenditures per treated patient and the 5th (P5) and 95th percentile (P95). The categorical variables of sex, specialist care utilization, and medication utilization were reported as frequencies and valid percentages of the total type 2 diabetes population. The number of medical specialties used per patient were reported as valid percentages of patients using one or more medical specialties. Specialist care utilization was also described with the mean number of DTCs per treated patient. Total expenditures per medical specialty and medication subgroup were presented as frequencies and valid percentages.

The data were drawn from the Vektis databases based on a detailed data extraction and processing request. The data were obtained using the statistical package SAS 7.15 (SAS Institute, Cary, NC, USA). According to the Maastricht University Medical Center Ethics Committee, this study is not subject to the Dutch Medical Research Involving Human Subjects Act (registration number 2019-1445).

\section{Results}

\subsection{Specialist Care}

\subsubsection{Specialist Care Utilization}

Table 2 displays the specialist care utilization and expenditures of the Dutch type 2 diabetes population. Of the patients who consulted medical specialties, $36.9 \%$ consulted one medial specialty, $26.3 \%$ consulted two medical specialties, and $36.8 \%$ utilized three or more different medical specialties in 2018 (Fig. 1). With regard to specific medical

Table 2 Specialist care utilization and expenditures in 2018

\begin{tabular}{|c|c|c|c|c|c|}
\hline & $\begin{array}{l}\text { Utilization } \\
\text { (no. of patients) } \\
{[n(\%)]}\end{array}$ & $\begin{array}{l}\text { Mean number of } \\
\text { DTCs per patient }\end{array}$ & $\begin{array}{l}\text { Total expendi- } \\
\text { tures [million } \\
€](\%)\end{array}$ & $\begin{array}{l}\text { Mean expenditures } \\
\text { per treated patient }(€) \\
\pm \mathrm{SD}\end{array}$ & $\begin{array}{l}\text { Median per treated patient } \\
\text { expenditures }[€](\mathrm{P} 5 ; \mathrm{P} 95)\end{array}$ \\
\hline Ophthalmology & 241,981 (26.9) & 1.8 & $141(5.6)$ & $581 \pm 1077$ & $160(73.0 ; 2634)$ \\
\hline Internal medicine & 209,197 (23.2) & 2.4 & 439 (17.6) & $2099 \pm 6619$ & $647(206.2 ; 7515.8)$ \\
\hline Cardiology & $190,200(21.1)$ & 1.9 & $391(15.6)$ & $2055 \pm 4676$ & $488(166.3 ; 10,490.4)$ \\
\hline Surgery & $131,292(14.6)$ & 1.6 & $366(14.6)$ & $2786 \pm 5340$ & $572(143.4 ; 12,711.2)$ \\
\hline Neurology & $96,310(10.7)$ & 1.4 & $129(5.2)$ & $1344 \pm 2401$ & $558(161.9 ; 6856.1)$ \\
\hline Dermatology & $87,416(9.7)$ & 1.6 & 39 (1.6) & $451 \pm 621$ & $228(102.7 ; 1513)$ \\
\hline Orthopedics & $83,066(9.2)$ & 1.6 & $167(6.7)$ & $2013 \pm 3592$ & 493 (132.0; 9446.0) \\
\hline Pulmonary medicine & $82,505(9.2)$ & 1.9 & $171(6.8)$ & $2073 \pm 4131$ & 749 (162.4; 8100.2) \\
\hline Urology & 71,289 (7.9) & 1.8 & $110(4.4)$ & $1538 \pm 2862$ & $568(119 ; 6772.7)$ \\
\hline $\begin{array}{l}\text { Gastroenterology and liver } \\
\text { disorders }\end{array}$ & $65,288(7.3)$ & 1.5 & $114(4.5)$ & $1738 \pm 3122$ & $911(202 ; 6914.7)$ \\
\hline Eye, nose, throat medicine & $63,347(7.0)$ & 1.4 & $38(1.5)$ & $593 \pm 1643$ & 302 (105.6; 1936.9) \\
\hline Rheumatology & $34,533(3.8)$ & 1.8 & $24(1.0)$ & $696 \pm 788$ & $501(217.5 ; 1583.0)$ \\
\hline Geriatrics & $25,862(2.9)$ & 1.3 & $55(2.2)$ & $2137 \pm 3281$ & $1,092(262.2 ; 7659.6)$ \\
\hline Rehabilitation medicine & $24,982(2.8)$ & 1.8 & $68(2.7)$ & $2700 \pm 8015$ & $443(165.9 ; 11,560.6)$ \\
\hline Gynecology & $24,816(2.8)$ & 1.6 & $31(1.2)$ & $1230 \pm 2201$ & $354(173.7 ; 5505.1)$ \\
\hline Anesthesiology & $23,039(2.6)$ & 1.8 & $30(1.2)$ & $1319 \pm 2248$ & $980(224.0 ; 3156.2)$ \\
\hline Plastic surgery & $22,552(2.5)$ & 1.5 & $26(1.0)$ & $1140 \pm 1500$ & 713 (113.4; 3919.2) \\
\hline Other $^{\mathrm{a}}$ & $42,532(4.7)$ & 1.4 & $161(6.4)$ & & \\
\hline Total & & & $2498(100.0)$ & 3893 & \\
\hline
\end{tabular}

DTCs diagnosis-treatment combination, $S D$ standard deviation, $P 5$ 5th percentile, $P 9595$ th percentile

a 'Other' category includes hospital-based specialties that were each used by < $1.5 \%$ of all patients with type 2 diabetes in 2018: neurosurgery, cardiopulmonary medicine, pediatrics, allergy medicine, radiotherapy, radiology, psychiatry, clinical genetics, audiology 


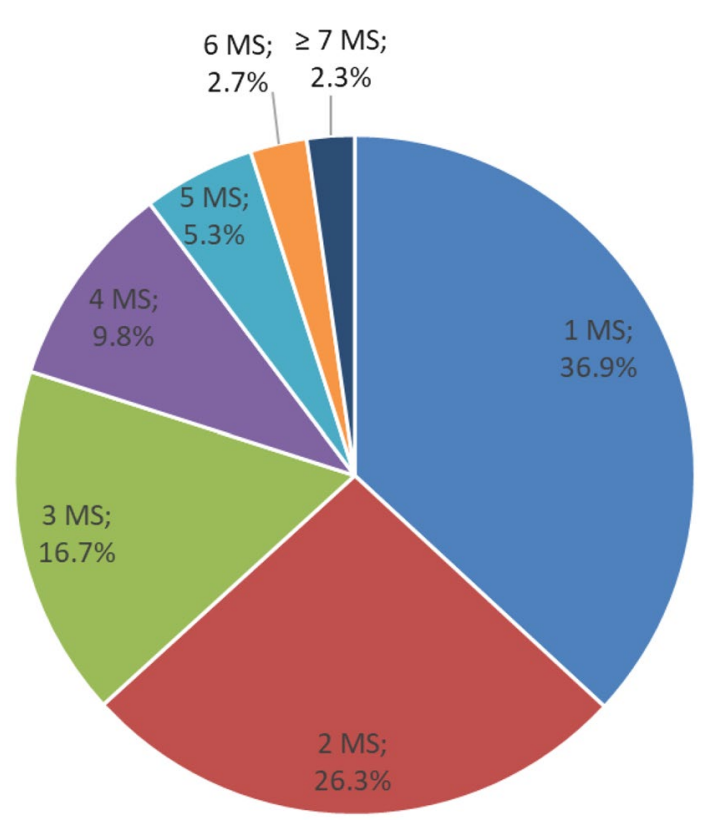

Fig. 1 Number of MS used by type 2 diabetes patients who used one or more MS $(n=641,515)$ in 2018. $M S$ medical specialties

specialties, ophthalmology was used by the largest share of patients $(26.9 \%)$, followed by internal medicine $(23.2 \%)$, and cardiology $(21.1 \%)$. Surgery was used by $14.6 \%$ of the population. Moreover, approximately $10 \%$ of the population had reimbursements for neurology, dermatology, orthopedic, or pulmonary medicine. Use of these medical specialties was stable over time, the biggest changes in use were for ophthalmology, where use decreased by $4.4 \%$ from 2016 , and for pulmonary medicine, where use increased by $4.2 \%$ in this timeframe.

\subsubsection{Specialist Care Expenditures}

The total expenditures on specialist care of the type 2 diabetes population were $€ 2372$ million in 2016 , increasing by $5.3 \%$ to $€ 2498$ million in 2018 (Table 2). The largest share of total spending was on internal medicine: $€ 439$ million (17.6\%) in 2018. Cardiology and surgery accounted for the second and third largest share of spending, with $15.6 \%$ (€391 million) and $14.6 \%$ (€366 million) of total expenditures, respectively. The spending on gastroenterology and liver disease increased most rapidly $(+14.5 \%)$ in the study period, leading to a share of $4.5 \%$ in 2018 . Expenditures on ophthalmology accounted for a total share of $5.6 \%$ of entire specialist care spending.

In 2018, the mean expenditures for patients treated in specialist care were $€ 3893$. For that year, the annual mean and median per treated patient expenditures for ophthalmology, dermatology, and ear, nose and throat medicine were lowest. For ophthalmology, the mean per treated patient expenditures were $€ 160$ and the median expenditures were $€ 581$ in 2018 . For the remaining medical specialties, the mean and median per treated patient expenditures per specific medical specialty varied widely; however, the mean per treated patient expenditures were higher than the median per treated patient expenditures. As displayed in Table 2, the highest mean per treated patient expenditures were found in surgery (€2786), whereas the highest median per treated patient expenditures were for geriatrics (€1092). The mean per treated patient expenditures in internal medicine were $€ 2099$ (SD 6619), whereas the median per treated patient expenditures were $€ 647$ (P5 = 206; P95 = 7516). For cardiology, the mean and median per patient expenditures were $€ 2055$ (SD 4676) and $€ 488$ with a P95 of $€ 10,490$, respectively.

\subsection{Medication}

\subsubsection{Medication Utilization}

In $2018,99.1 \%$ of the type 2 diabetes population used medication: $81.9 \%$ used GLDs and $97.8 \%$ used other medication. Medication utilization by the type 2 diabetes population is displayed in Fig. 2. Regarding the total medication subgroups, a large majority of patients with type 2 diabetes (80.5\%) used GLDs and other medication. Moreover, $17.3 \%$ of patients with type 2 diabetes did not use GLDs but used other medication. A small number of patients used only GLDs or no medication at all (1.3\% and $0.9 \%$, respectively). The share of type 2 diabetes patients who did not use GLDs increased by $6.8 \%$ over the study period.

Specifically, for diabetes medication or GLDs use, the majority of patients with type 2 diabetes used only oral medication $(59.6 \%)$, followed by oral medication in combination with insulin (18.9\%). Moreover, $3.0 \%$ were treated with insulins only. From 2016 to 2018, this group decreased by 7.9\%. Although the combination medication insulin/GLP-1 was least widely used $(0.4 \%)$, the number of patients using this type of medication increased most during the study period: from one user in 2016 to 1902 users in 2017 and 3220 in 2018.

\subsubsection{Medication Expenditures}

Total medication expenditures for the type 2 diabetes population were $€ 931$ million in 2018 , including $€ 238$ million on diabetes medication (Fig. 3a, b, respectively). The total medication expenditures increased by $4.8 \%$ from 2016 , where spending on diabetes medication increased by $6.8 \%$. Regarding the total medication subgroups, medication spending was highest for patients using both GLDs and other medication (€827 million). Total expenditures were lowest for patients using only GLDs ( $€ 2$ million). For the subgroup 


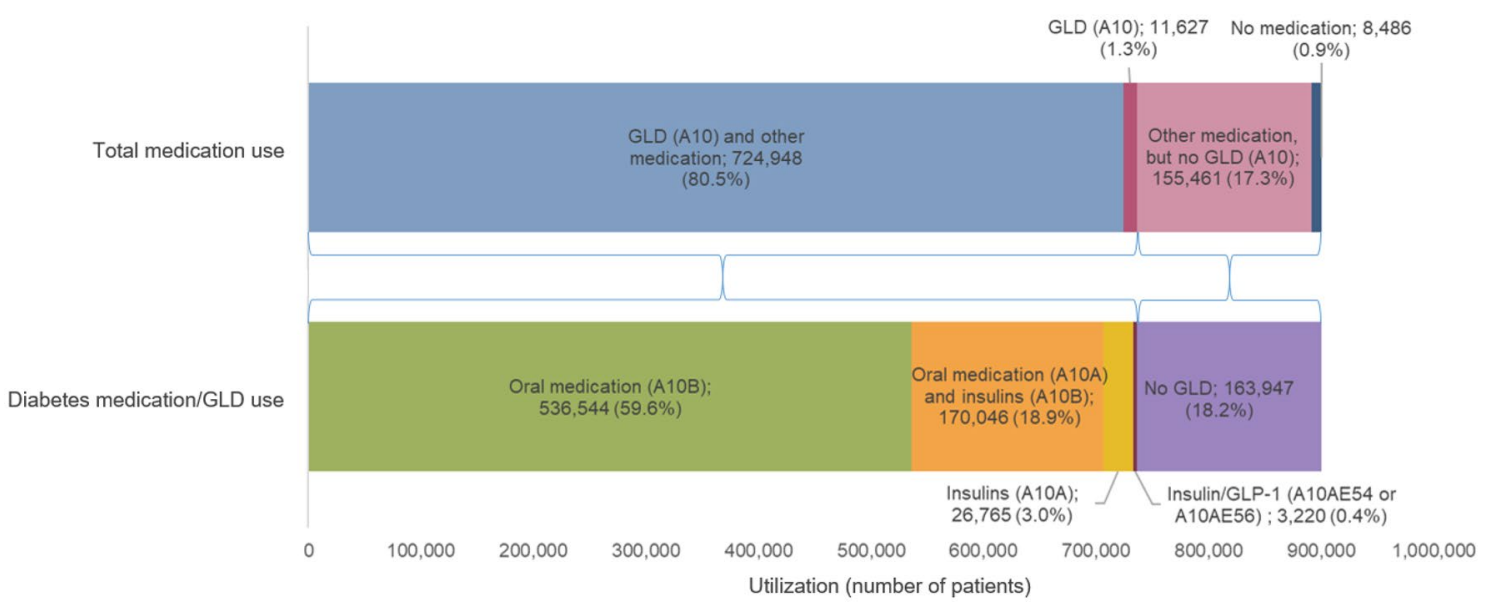

Fig. 2 Total medication and diabetes medication utilization in 2018. GLD glucose-lowering drug

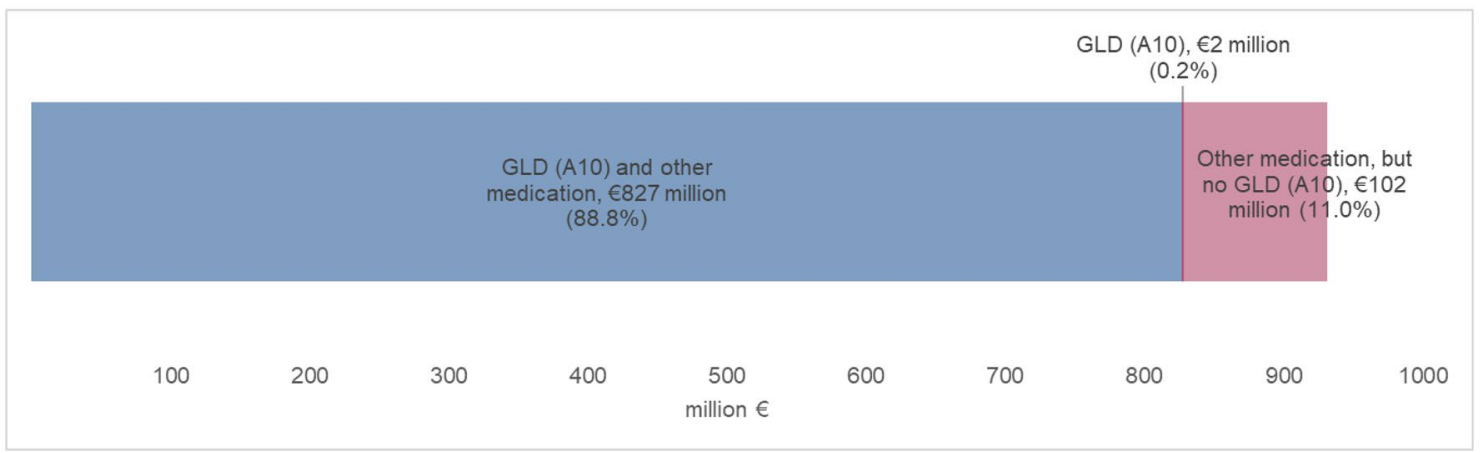

(a)

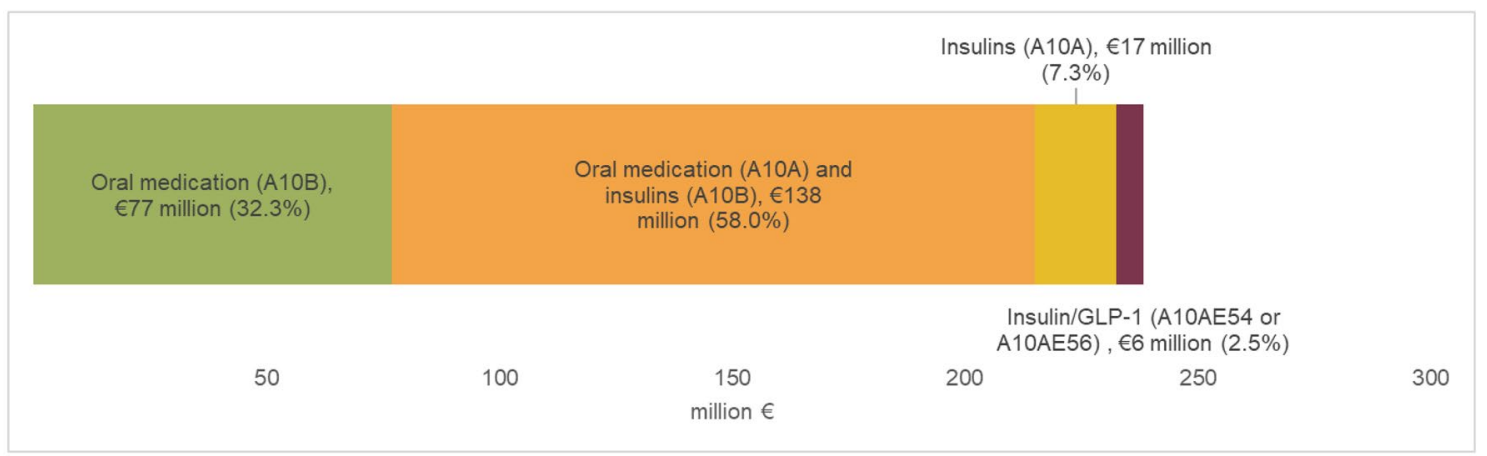

(b)

Fig. 3 a Total medication expenditures; b diabetes medication expenditures in 2018. GLD glucose-lowering drug, GLP-1 glucagon-like peptide 1

that used other medication, but no GLDs, total expenditures were $€ 102$ million.

Regarding diabetes medication use, the largest share of expenditures was for patients with type 2 diabetes using both oral medication and insulin, at $€ 138$ million, which accounts for $58.0 \%$ of expenditures in this category. Oral medication accounted for the second largest share (32.3\%) in diabetes medication expenditures: $€ 77$ million). Expenditures for use of the combination medication insulin/GLP-1 composed the smallest share but increased most during the study period (i.e. $€ 565$ in $2016, € 3$ million in 2017 , and $€ 6$ million in 2018). 


\subsubsection{Medication Expenditures per Treated Patient}

Regarding total medication use, per patient expenditures were highest when a combination of GLDs and other medication (not GLDs) was used (Table 3). Mean per patient expenditures in this subgroup were $€ 1140$ in 2018 . Per patient expenditures on diabetes medication were highest for patients who used a mix of insulin and GLP-1 - on average, $€ 1816$ in 2018. Considering patients who use diabetes medication, the least expensive diabetes medication per patient was oral medication (mean annual per patient expenditure of $€ 143$ ). The mean expenditures per medication subgroup were stable over time, except for patients who used a mix of insulin and GLP-1: mean expenditures increased from $€ 565$ to $€ 1816$ ( $+221.8 \%$ ) from 2016 to 2018 .

\section{Discussion}

In this study, we provided a detailed description of the specialist care utilization and expenditures of the Dutch type 2 diabetes population using all-payer claims data from the years 2016 to 2018. Moreover, we analyzed the population's medication use and expenditures over the same period. Our findings show that in 2018, €2498 million was spent on specialist care for patients with type 2 diabetes, which was $10.6 \%$ of total national expenditures on specialist care in the Netherlands [35]. This spending covered a heterogeneous pattern of service use across medical specialties and was related to diabetes and/or other health problems. Annually, the majority of type 2 diabetes patients (63.1\%) used services from multiple medical specialties. With regard to specific specialties, the largest share of patients had consultations to ophthalmology (26.9\%), followed by internal medicine (23.2\%), cardiology (21.1\%), surgery (14.6\%), and neurology (10.7\%). Regarding medication use, we found expenditures of $€ 238$ million for GLDs in 2018. In the same year, type 2 diabetes patients had $€ 931$ million in expenditures for other medication. For both specialist care and medication, we found that mean per patient expenditures were consistently higher than median per patient expenditures, suggesting that a small part of the population is responsible for a large share of total spending.

With regard to specialist care use, we observed that eight different medical specialties were each utilized by approximately $9-27 \%$ of the population. Almost two-thirds of medical specialist care users visited two or more different medical specialties per year. Additionally, we found that mean expenditures for type 2 diabetes patients treated in specialist care were relatively high: mean spending was $€ 3893$, whereas mean spending for a similar age group (60-74 years) of the general population was $€ 2704$ in 2017 [36]. This heterogeneous utilization and increased spending could likely be explained by the presence of comorbidities, as prior studies have shown that comorbidities increase specialist care use for patients with type 2 diabetes [6-9, 12]. Indeed, we found that a large share of expenditures on care for the Dutch type 2 diabetes population was not directly related to diabetes treatment. Almost $75 \%$ of medication expenditures, for example, were related to other medication (i.e. not GLDs). Thus, it seems that while care for type 2 diabetes in itself is not necessarily expensive, whole-person care for patients with type 2 diabetes, who often have complications and/or comorbidities, is costly. Prior research in other countries shows similar findings. In Sweden, other medication also accounted for the majority of patients' total medication costs; the same trends have been recognized in France, Italy, Spain, and the UK $[9,37,38]$.

Our findings also indicate that a small part of the type 2 diabetes population is responsible for a large share of total
Table 3 Mean and median per treated patient medication expenditures in 2018

\begin{tabular}{lcl}
\hline & $\begin{array}{c}\text { Mean expenditures per } \\
\text { treated patient [€] (SD) }\end{array}$ & $\begin{array}{l}\text { Median per treated patient } \\
\text { expenditures [€] (P5; P95) }\end{array}$ \\
\hline Total medication & & $701(112 ; 3175)$ \\
GLDs (A10) and other medication & $1140 \pm 2383$ & $53(14 ; 692)$ \\
GLDs (A10) & $162 \pm 282$ & $321(37 ; 2003)$ \\
Other medication, but no GLDs (A10) & $658 \pm 1899$ & - \\
No medication & - & $62(20 ; 583)$ \\
Diabetes medication & $143 \pm 242$ & $632(178 ; 2106)$ \\
Oral medication (A10B) & $812 \pm 655$ & $539(105 ; 1558)$ \\
Oral medication (A10A) and insulins (A10B) & $649 \pm 490$ & - \\
Insulins (A10A) & $1816 \pm 814$ & - \\
Insulin/GLP-1 (A10AE54 or A10AE56) & & - \\
No GLDs & & $-698 ; 3233)$ \\
\hline
\end{tabular}

$S D$ standard deviation, $P 55$ th percentile, $P 95$ 95th percentile, GLDs glucose-lowering drugs, GLP- 1 glucagon-like peptide 1 
expenditures. We found a skewed distribution of expenditures related to specialist care, as well as medication use, and that mean per patient expenditures were consistently higher than median per patient expenditures. Prior research has also recognized this skewed distribution of costs, as a disproportional amount of the economic burden of type 2 diabetes was found to be attributable to a minority of patients [17, 39-43]. This could result from the focus on treating patients' emergent problems or could be due to the presence of multiple complications in patients with advanced diabetes, as well as comorbidities [39, 40]. Moreover, previous studies have found that factors such as the presence of obesity, insulin use, renal impairment, and hospitalization predict high costs for patients with diabetes [17, 43].

Our study has several strengths. The APCD used in our study covers $99.9 \%$ of Dutch citizens, enabling us to identify a nationwide type 2 diabetes cohort and assess their complete claims data related to medical specialist care and medication use. Prior research of healthcare expenditures and utilization on type 2 diabetes is often limited to subgroups of patients, specific medical specialties, complications, or diabetes medication types [6-9, 11, 13, 15, 16, 18-22, 25]. The economic function of the APCD ensures data are accurate and complete; Vektis data are used for risk equalization among health insurers. As Dutch health insurers must accept everyone obliged to the statutory health insurance, they are highly dependent on a fair compensation for risk differences in order to survive in the market [44]. Thus, quality control of the data is extremely important and data are checked by both the health insurers and Vektis to prevent errors (e.g., in coding) [45]. The combination of a virtually complete dataset, high data accuracy, and completeness allowed us to gain detailed insight into complete care use and spending on a population level. However, the use of APCD does have some disadvantages. The absence of clinical markers and diagnosis codes in claims data complicates perfect identification of patients with type 2 diabetes. Accordingly, we could not identify type 2 diabetes patients living in nursing homes as most residents do not receive integrated diabetes care or diabetes medication registered outside their nursing home. However, as we could identify based on integrated diabetes care, and according to strict medication guidelines [46], this appears to be limited. We found 900,522 type 2 diabetes patients in 2018, where Vektis reported 991,000 diabetes patients in total [47]. This is in agreement with the known distribution of 10\% type 1 diabetes and $90 \%$ type 2 diabetes $[4,5]$. Additionally, the direct generalizability of total expenditures on specialist care and medication, as well as the care utilization in the Netherlands, may be limited at an international level. This is due to differences in care organization and care costs for both general and diabetes care [7]. Consequently, the number of hospitalizations, as well as expenditures on pharmaceutical care, for patients with type 2 diabetes vary widely between countries $[10,15$, 38]. However, our findings are based on a heterogeneous cohort. Therefore, findings regarding the distribution of expenditures and utilization of specialist care and medication are meaningful at an international level, as this could have implications regarding complications and comorbidities of type 2 diabetes populations. As the burden of chronic disease currently rises, multiple actors can benefit from this knowledge, as it could aid future research, practice, and policymaking in a way that supports the financial sustainability of healthcare systems.

The detailed description of the specialist care utilization and expenditures of the Dutch type 2 diabetes population we provided in this study has implications for current integrated care programs that solely focus on diabetes. Such programs are established in, amongst others, Austria, France, Germany, and the Netherlands [48]. These programs tend to be highly standardized and are focused on preventing complications of diabetes, for example, through regular cardiovascular risk assessment, diabetic foot care, and fundus photography [30, 48]. Our findings suggest that patients with type 2 diabetes have diverse care needs, as illustrated by the heterogeneity in their care utilization, therefore a more tailored, patient-centered approach to diabetes care could be meaningful. Such an approach can lead to better controlled glycated hemoglobin (HbA1c) levels, cholesterol and blood pressure, and may consequently contribute to long-term health improvement and prevention of type 2 diabetes-related complications [40, 49, 50]. As type 2 diabetes-related complications and comorbidities are found to significantly increase healthcare utilization and expenditures of type 2 diabetes patients, these health improvements could lead to a reduction in overall costs, subsequently promoting the sustainability of healthcare systems [6-9, 26, 51-54]. To address this in detail, future research should assess how specific comorbidities and number of comorbidities influence care utilization. Moreover, in the current study, we were unable to analyze whether healthcare use and spending was related to diabetes and/or its complications. However, a detailed insight into the influence of type 2 diabetes, by comparing people with and without type 2 diabetes, would be meaningful as findings that contextualize what care use and expenditures are associated with diabetes could have more detailed implications on how to improve diabetes care programs. In practice, a control group can be matched to the Dutch type 2 diabetes population using the APCD we used in our study. Additionally, as our results indicate that a small part of the type 2 diabetes population is responsible for a large share of total expenditures, future research should focus on these 'high-need, high-cost' patients with type 2 diabetes. Characterizing this group can possibly lead to improvements in their care and ultimately reduce costs to contribute to the sustainability of the healthcare system. 


\section{Conclusion}

We found heterogeneous health care patterns across medical specialties and a high utilization of other medication (not GLDs) for the Dutch type 2 diabetes population. In addition, per patient expenditures indicate that a small part of the population is responsible for a large share of total expenditures. These findings can likely, in part, be explained by the presence of comorbidities and complications, which impact patients' care needs and service use. Hence, integrated care programs should be reformed to provide more tailored, patient-centered diabetes care, taking into account the diverse nature of the population.

Acknowledgements The authors thank Michiel ten Hove, Robin Stoof, and Paul Sterkenburg (all from Vektis) for their assistance in developing the study design and answering our questions about the data.

\section{Declarations}

Funding The current study was funded by AstraZeneca BV, The Netherlands. The study sponsor was not involved in the collection, analysis, or interpretation of data; writing the report; and did not impose any restrictions regarding the publication of the report.

Conflicts of interest Rose J. Geurten, Jeroen N. Struijs, Arianne M.J. Elissen, Henk J.G. Bilo, Chantal van Tilburg, and Dirk Ruwaard declare no relationships or activities that might have influenced the work reported in this paper.

Data availability statement The datasets generated and analyzed during this study are not publicly available, as formal consent from the Dutch health insurers is needed to gain access to these files. Data are however available from Vektis Health Care Information Center upon reasonable request and with formal consent of the Dutch health insurers

Consent to participate Not applicable.

Consent for publication (from Patients/Participants) Not applicable.

Code availability (Software Application or Custom Code) Not applicable.

Compliance with ethical standards According to the Maastricht University Medical Center Ethics Committee, this study is not subject to the Dutch Medical Research Involving Human Subjects Act (registration number 2019-1445).

Author contributions $\mathrm{RG}, \mathrm{AE}, \mathrm{DR}, \mathrm{JS}, \mathrm{HB}$, and $\mathrm{CvT}$ were involved in the design of the study. A detailed data extraction and processing request for data acquisition was made by $\mathrm{RG}, \mathrm{AE}$, and $\mathrm{HB}$ and approved by DR and JS. CvT performed the data acquisition and assisted with the data analysis. All authors were involved in checking the accuracy and completeness of the data. RG conducted the data analysis, drafting, and manuscript writing. AE, HB, JS, and DR critically reviewed and revised the drafts and contributed to manuscript writing. All authors approved the final version and were involved in the decision to submit the manuscript for publication.
Open Access This article is licensed under a Creative Commons Attribution-NonCommercial 4.0 International License, which permits any non-commercial use, sharing, adaptation, distribution and reproduction in any medium or format, as long as you give appropriate credit to the original author(s) and the source, provide a link to the Creative Commons licence, and indicate if changes were made. The images or other third party material in this article are included in the article's Creative Commons licence, unless indicated otherwise in a credit line to the material. If material is not included in the article's Creative Commons licence and your intended use is not permitted by statutory regulation or exceeds the permitted use, you will need to obtain permission directly from the copyright holder. To view a copy of this licence, visit $\mathrm{http} / / /$ creativecommons.org/licenses/by-nc/4.0/.

\section{References}

1. Maarse H, Jeurissen P, Ruwaard D. Concerns over the financial sustainability of the Dutch healthcare system. DICE Rep. 2013;11:32-6.

2. Liaropoulos L, Goranitis I. Health care financing and the sustainability of health systems. Int J Equity Health. 2015;14:80. https://doi.org/10.1186/s12939-015-0208-5.

3. WHO. Nutrition health topics. Programmes and projectsNutrition. https://www.who.int/dietphysicalactivity/publicatio ns/trs916/en/gsfao_background.pdf?ua=1. Accessed 19 May 2021.

4. Williams R, Colagiuri S, Almutairi R, Montoya PA, Basit A, Beran D, et al. IDF diabetes atlas. 9th ed. Brussels: International Diabetes Federation; 2019. p. 12-21 (34-61).

5. Rijksinstituut voor Volksgezondheid en Milieu (RIVM). Diabetes mellitus - Cijfers \& Context - Huidige situatie [The National Institute of Public Health and the Environment on Diabetes Mellitus - Numbers and Context: The current situation]. https:// www.volksgezondheidenzorg.info/onderwerp/diabetes-mellitus/ cijfers-context/huidige-situatie\#node-aandeel-diabetes-type-1totaal-naar-leeftijd-en-geslacht. Accessed 28 Oct 2020.

6. Struijs JN, Baan CA, Schellevis FG, Westert GP, Van Den Bos GAM. Comorbidity in patients with diabetes mellitus: Impact on medical health care utilization. BMC Health Serv Res. 2006;6:84. https://doi.org/10.1186/1472-6963-6-84.

7. Tamayo T, Rosenbauer J, Wild SH, Spijkerman AMW, Baan C, Forouhi NG, et al. Diabetes in Europe: an update. Diabetes Res Clin Pract. 2014;103(2):206-17. https://doi.org/10.1016/j.diabr es.2013.11.007.

8. Hazel-Fernandez L, Li Y, Nero D, Moretz C, Slabaugh L, Meah Y, et al. Relationship of diabetes complications severity to healthcare utilization and costs among Medicare Advantage beneficiaries. Am J Manag Care. 2015;21(1):e62-70.

9. Kanavos P, Aardweg S Van Den, Schurer W. Cost burden of diabetes and its complications and The Challenges of DiabetesOutlook for the future. Diabetes Expenditure, Burden of Disease and Management in 5 EU Countries. 2012. https://www.lse.ac. uk/business-and-consultancy/consulting/assets/documents/diabe tes-expenditure-burden-of-disease-and-management-in-5-eucountries.pdf. Accessed 24 Jan 2021.

10. Alzaid A, Ladrón de Guevara P, Beillat M, Lehner Martin V, Atanasov P. Burden of disease and costs associated with type 2 diabetes in emerging and established markets: systematic review analyses. Expert Rev Pharmacoecon Outcomes Res. 2020;21(4):785-98. https://doi.org/10.1080/14737167.2020.1782748.

11. Ramzan S, Timmins P, Hasan SS, Babar ZUD. Cost analysis of type 2 diabetes mellitus treatment in economically developed countries. Expert Rev Pharmacoecon Outcomes Res. 
2019;19(1):5-14. https://doi.org/10.1080/14737167.2018.15137 90.

12. Calderón-Larrañaga A, Abad-Díez JM, Gimeno-Feliu LA, Marta-Moreno J, González-Rubio F, Clerencia-Sierra M, et al. Global health care use by patients with type-2 diabetes: does the type of comorbidity matter? Eur J Intern Med. 2015;26(3):20310. https://doi.org/10.1016/j.ejim.2015.02.011.

13. Pagano E, De Rosa M, Rossi E, Cinconze E, Marchesini G, Miccoli $\mathrm{R}$, et al. The relative burden of diabetes complications on healthcare costs: the population-based CINECA-SID ARNO Diabetes Observatory. Nutr Metab Cardiovasc Dis. 2016;26(10):944 50. https://doi.org/10.1016/j.numecd.2016.05.002.

14. da Rocha FJ, Ogurtsova K, Linnenkamp U, Guariguata L, Seuring T, Zhang P, et al. IDF Diabetes Atlas estimates of 2014 global health expenditures on diabetes. Diabetes Res Clin Pract. 2016;117:48-54. https://doi.org/10.1016/j.diabres.2016.04.016.

15. Müller N, Heller T, Freitag MH, Gerste B, Haupt CM, Wolf G, et al. Healthcare utilization of people with Type 2 diabetes in Germany: An analysis based on health insurance data. Diabet Med. 2015;32(7):951-7. https://doi.org/10.1111/dme.12747.

16. Seferović PM, Petrie MC, Filippatos GS, Anker SD, Rosano G, Bauersachs J, et al. Type 2 diabetes mellitus and heart failure: a position statement from the Heart Failure Association of the European Society of Cardiology. Eur J Heart Fail. 2018;20(5):853-72. https://doi.org/10.1002/ejhf.1170.

17. Meyers JL, Parasuraman S, Bell KF, Graham JP, Candrilli SD. The high-cost, type 2 diabetes mellitus patient: An analysis of managed care administrative data. Arch Public Health. 2014;72(1):6. https://doi.org/10.1186/2049-3258-72-6.

18. Li R, Bilik D, Brown MB, Zhang P, Ettner SL, Ackermann RT, et al. Medical costs associated with type 2 diabetes complications and comorbidities. Am J Manag Care. 2013;19:421-30.

19. Zgibor JC, Orchard TJ, Saul M, Piatt G, Ruppert K, Stewart A, et al. Developing and validating a diabetes database in a large health system. Diabetes Res Clin Pract. 2007;75(3):313-9. https:// doi.org/10.1016/j.diabres.2006.07.007.

20. De Groot S, Enters-Weijnen CF, Geelhoed-Duijvestijn PH, Kanters TA. A cost of illness study of hypoglycaemic events in insulin-treated diabetes in the Netherlands. BMJ Open. 2018;8(3): e019864. https://doi.org/10.1136/bmjopen-2017-019864.

21. Nichols GA, Desai J, Lafata JE, Lawrence JM, O'Connor PJ, Pathak RD, et al. Construction of a multisite datalink using electronic health records for the identification, surveillance, prevention, and management of diabetes mellitus: the SUPREME-DM project. Prev Chronic Dis. 2012;9:E110. https://doi.org/10.5888/ pcd9.110311.

22. Slabaugh SL, Curtis BH, Clore G, Fu H, Schuster DP. Factors associated with increased healthcare costs in Medicare Advantage patients with type 2 diabetes enrolled in a large representative health insurance plan in the US. J Med Econ. 2014;18(2):106-12. https://doi.org/10.3111/13696998.2014.979292.

23. Charbonnel B, Simon D, Dallongeville J, Bureau I, Dejager S, Levy-Bachelot L, et al. Direct medical costs of type 2 diabetes in France: an insurance claims database analysis. PharmacoEconomics Open. 2018;2(2):209-19. https://doi.org/10.1007/ s41669-017-0050-3.

24. Jacobs E, Hoyer A, Brinks R, Icks A, Kuß O, Rathmann W. Healthcare costs of Type 2 diabetes in Germany. Diabet Med. 2017;34(6):855-61. https://doi.org/10.1111/dme.13336.

25. Rangaswami J, Bhalla V, de Boer IH, Staruschenko A, Sharp JA, Singh RR, et al. Cardiorenal protection with the newer antidiabetic agents in patients with diabetes and chronic kidney disease: a scientific statement from the American Heart Association. Circulation. 2020;142(17):e265-86. https://doi.org/10.1161/CIR.00000 00000000920 .
26. Jo C. Cost-of-illness studies: concepts, scopes, and methods. Clin Mol Hepatol. 2014;20(4):327-37. https://doi.org/10.3350/cmh. 2014.20.4.327.

27. Freedman JD, Green L, Landon BE. All-payer claims databases-uses and expanded prospects after gobeille. N Engl J Med. 2016;375(23):2215-7. https://doi.org/10.1056/NEJMp1613276.

28. Dworsky M. Using all-payer claims databases to study insurance and health care utilization dynamics. J Gen Intern Med. 2017;32(10):1069-70. https://doi.org/10.1007/ s11606-017-4128-5.

29. de Boo A. Vektis' Informatiecentrum voor de zorg' [Vektis 'Information for care']. Tijdschr voor gezondheidswetenschappen. 2011;7:358-9.

30. Klomp M, Romeijnders A, Braal E de, Meulepas M, Hart $\mathrm{B}$, Bilo $\mathrm{H}$, et al. Resultaten diabetes algemeen \& Resultaten diabetes indicatoren. In: Transparante Ketenzorg Rapportage 2019 Zorggroepen: Diabetes Mellitus, VRM, COPD en Astma [Report on Transparency in Integrated Diabetes Care and Care Groups]. InEen. 2018. https://ineen.nl/wp-content/uploads/ 2020/07/200715-Benchmark-Transparante-ketenzorg-2019-web. pdf. Accessed 24 Jan 2021.

31. Struijs JN, Baan CA. Integrating care through bundled payments-lessons from the Netherlands. N Engl J Med. 2011;364(11):990-1. https://doi.org/10.1056/nejmp1011849.

32. Stichting Farmaceutische Kerngetallen. Geneesmiddelen bij diabetes. In: Data en feiten 2019 - Het jaar 2018 in cijfers [The Foundation of Pharmaceutical Key figures on data and facts of diabetes drugs in 2018]. 2019. https://www.sfk.nl/publicaties/ data-en-feiten/data-en-feiten-2019. Accessed 28 Oct 2020.

33. Nederlandse Zorgautoriteit (NZa). Advies bekostiging medischspecialistische zorg "Belonen van zorg die waarde toevoegt" [Presentation of The Dutch Healthcare Authority regarding advice on medical specialist care reimbursement]. 2018. https:// www.rijksoverheid.nl/documenten/rapporten/2018/10/04/belon en-van-zorg-die-waarde-toevoegt. Accessed 28 Oct 2020.

34. Berden C, Croes R, Kemp R, Mikkers M, van der Noll R, Shestalova V, et al. Hospital Competition in the Netherlands: An Empirical Investigation. TILEC Discussion Paper No. 2019008; CentER Discussion Paper No. 2019-018;30.

35. CBS. StatLine - Zorguitgaven in drie benaderingen; zorgaanbieders [Care expenditures approached in three ways; care providers]. 2020. https://opendata.cbs.nl/\#/CBS/nl/dataset/84054 NED/table? $\mathrm{dl}=3 \mathrm{AB} 46 \& \mathrm{ts}=1605793224356$. Accessed $11 \mathrm{Mar}$ 2021.

36. Volksgezondheid en Zorg. Ziekenhuiszorg - Kosten - Zorguitgaven - Zorguitgaven ziekenhuiszorg 2017 [Hospital care expenditures 2017]. 2020. https://www.volksgezondheidenzorg.info/ onderwerp/ziekenhuiszorg/kosten/zorguitgaven\#node-zorguitgav en-ziekenhuiszorg. Accessed 2 Sep 2021.

37. Nathanson D, Sabale U, Eriksson JW, Nyström T, Norhammar A, Olsson U, et al. Healthcare cost development in a type 2 diabetes patient population on glucose-lowering drug treatment: a nationwide observational study 2006-2014. PharmacoEconomics Open. 2018;2(4):393-402. https://doi.org/10.1007/s41669-017-0063-y.

38. Jönsson B. Revealing the cost of type II diabetes in Europe. Diabetologia. 2002;45(7):S5-12. https://doi.org/10.1007/ s00125-002-0858-x.

39. Maguire J, Dhar V. Comparative effectiveness for oral anti-diabetic treatments among newly diagnosed type 2 diabetics: datadriven predictive analytics in healthcare. Health Syst. 2013;2:7392. https://doi.org/10.1057/hs.2012.20.

40. Bron M, Guerin A, Latremouille-Viau D, Ionescu-Ittu R, Viswanathan $\mathrm{P}$, Lopez C, et al. Distribution and drivers of costs in type 2 diabetes mellitus treated with oral hypoglycemic agents: a retrospective claims data analysis. J Med Econ. 2014;17(9):646-57. https://doi.org/10.3111/13696998.2014.925905. 
41. Rucci P, Avaldi VM, Travaglini C, Ugolini C, Berti E, Moro ML, et al. Medical costs of patients with type 2 diabetes in a single payer system: a classification and regression tree analysis. PharmacoEconomics Open. 2020;4(1):181-90. https://doi.org/10. 1007/s41669-019-0166-8.

42. de Lagasnerie G, Aguadé AS, Denis P, Fagot-Campagna A, Gastaldi-Menager C. The economic burden of diabetes to French national health insurance: a new cost-of-illness method based on a combined medicalized and incremental approach. Eur J Heal Econ. 2018;19(2):189-201. https://doi.org/10.1007/ s10198-017-0873-y.

43. Guerrero Fernández de Alba I, Orlando V, Monetti VM, Mucherino S, Gimeno-Miguel A, Vaccaro O, et al. Comorbidity in an older population with type-2 diabetes mellitus: identification of the characteristics and healthcare utilization of high-cost Patients. Front Pharmacol. 2020;11:5861878. https://doi.org/10. 3389/fphar.2020.586187.

44. Van Kleef RC, Van Vliet RC, Van De Ven WP. Risk equalization in the Netherlands: an empirical evaluation. Expert Rev Pharmacoecon Outcomes Res. 2013;13(6):829-39. https://doi.org/10. 1586/14737167.2013.842127.

45. Hrzic R, Clemens T, Westra D, Brand H. Comparability in crossnational health research using insurance claims data: the cases of Germany and the Netherlands. Gesundheitswesen. 2019;82(Suppl 1):S83-90. https://doi.org/10.1055/a-1005-6792.

46. Barents ESE, Bilo HJG, Bouma M, et al. NHG standaard-Diabetes mellitus type 2-Richtlijnen beleid-Medicamenteuze therapie [Medication guidelines for type 2 diabetes Melitus type]. https://richtlijnen.nhg.org/standaarden/diabetes-mellitus-type-2. Accessed 19 Jul 2021.

47. Vektis. Diabetes in top 5 chronische aandoeningen 40-plussers [Diabetes in the top 5 of most common chronic conditions age
40+] 2019. https://www.vektis.nl/actueel/diabetes-in-top-5-chron ische-aandoeningen-40-plussers. Accessed 19 Aug 2021.

48. Tsiachristas A, Dikkers C, Boland MRS, Rutten-van Mölken MPMH. Exploring payment schemes used to promote integrated chronic care in Europe. Health Policy. 2013;113(3):296-304. https://doi.org/10.1016/j.healthpol.2013.07.007.

49. Boels AM, Hart HE, Rutten GE, Vos RC. Personalised treatment targets in type 2 diabetes patients: the Dutch approach. Prim Care Diabetes. 2017;11(1):71-7. https://doi.org/10.1016/j.pcd.2016.08. 001.

50. Keng MJ, Tsiachristas A, Leal J, Gray A, Mihaylova B. Impact of achieving primary care targets in type 2 diabetes on health outcomes and healthcare costs. Diabetes Obes Metab. 2019;21(11):2405-12. https://doi.org/10.1111/dom.13821.

51. Inzucchi SE, Bergenstal RM, Buse JB, Diamant M, Ferrannini E, Nauck M, et al. Management of hyperglycemia in type 2 diabetes: a patient-centered approach. Diabetes Care. 2012;35(6):1364-79. https://doi.org/10.2337/dc12-0413.

52. Berntsen G, Høyem A, Lettrem I, Ruland C, Rumpsfeld M, Gammon D. A person-centered integrated care quality framework, based on a qualitative study of patients' evaluation of care in light of chronic care ideals. BMC Health Serv Res. 2018;18:479. https://doi.org/10.1186/s12913-018-3246-z.

53. Mitri J, Gabbay R. Understanding population health through diabetes population management. Endocrinol Metab Clin North Am. 2016;45(4):933-42. https://doi.org/10.1016/j.ecl.2016.06.006.

54. Janssen LMM, Hiligsmann M, Elissen AMJ, Joore MA, Schaper NC, Bosma JHA, et al. Burden of disease of type 2 diabetes mellitus: cost of illness and quality of life estimated using the Maastricht Study. Diabet Med. 2020;37(10):1759-65. https://doi.org/ 10.1111/dme.14285. 